\title{
CURTOS-CIRCUITOS NA CORRESPONDÊNCIA Mário de ANdrade e Manuel Bandeira
}

\author{
Marcos Antonio de Moraes \\ mamoraes@usp.br
}

Tendo em mãos o "Prefácio" inédito de Mário de Andrade para os Estudos de folclore de Luciano Gallet, Manuel Bandeira, em 30 de julho de 1933, propõe, em carta ao autor, alguns ajustes no texto. Retifica informação biográfica do compositor carioca falecido em 1931 e apresenta "observações sobre linguagem", entre as quais duas que supõe encontrar pela frente a resistência do interlocutor em aceitá-las: "não sei se não é inútil comunicá-las a você. Estou certo que você não me atenderá, e no entanto não há nada de que eu esteja mais certo nesta vida" (MORAES, 2001, p. 564).

Bandeira retomava, na correspondência iniciada em maio de 1922, o debate sobre o uso de pronome oblíquo iniciando a frase. Em confronto, duas concepções sobre a formalização do discurso literário. No projeto estético mariodeandradiano, detecta-se o propósito de observação de ampla gama de fatos linguísticos, resultando no esforço de "sistematização" de enunciados regionais e populares, no plano da expressão literária culta. O poeta pernambucano que vivia no Rio de Janeiro, flagrando o caráter artificial de algumas soluções desse empreendimento, reage irritado, na carta de 7 de agosto, recusando a argumentação construída pelo idealizador da Gramatiquinha da fala brasileira: "as suas alegações de lógica não pegam. Não pegam, não pegam, não pegam” (MORAES, 2001, p. 566). 
O desacordo de Manuel Bandeira em relação a certos aspectos do experimentalismo linguístico de Mário resistirá ao tempo, para além do diálogo epistolar e da morte do amigo paulistano, ocorrida em fevereiro de 1945. Na conferência "Mário de Andrade e a questão da língua", inserida em De poetas e de poesia, em 1954, julga "irritante" o "abrasileiramento da linguagem literária" pretendido pelo criador de Macunaíma, proposta que teria redundado em desserviço "à verdade e beleza de suas criações". Esse "detalhe mais visível” do nacionalismo do companheiro de geração modernista tornara-se, enfim, empecilho para o enfrentamento do "problema mais vasto e mais completo de aprofundar harmonicamente o tipo brasileiro" (BANDEIRA, 1958, p. 1207). Restaura, nessa palestra, a contenda gramatical sediada nas cartas dos anos de 1920 e 1930:

Considero [...] erro iniciar o período pelas formas oblíquas “o”, “a”, “os”, “as”, ou "se" com o futuro e o condicional, por não se basearem estes casos em fatos da língua falada, popular ou culta: o povo não diz "O vi”, diz (e muita gente boa também) "Vi ele", forma que Mário só admitiu quando o pronome é sujeito de um infinito seguinte ("Vi ele fazer"); ninguém, nem povo nem pessoa culta, diz "Se diria". Discuti muito esses dois pontos com o meu amigo, sem que nenhum de nós lograsse convencer o outro (BANDEIRA, 1958, p. 1213).

Estudar a correspondência de escritores do modernismo, sob o ângulo dos embates que levaram a curtos-circuitos, amplia o modo de compreensão do funcionamento dos intercâmbios intelectuais. A engrenagem epistolar move-se, preliminarmente, alimentada pelas "afinidades eletivas", na complexa conjugação de interesses e objetivos comuns, admiração de parte a parte, concordâncias no terreno estético e político. A duração temporal da troca de cartas depende do encaminhamento harmônico no trato de assuntos discutidos, mas não apenas. O vigor da correspondência reside, em grande medida, nos impasses, os quais demandam proposições conciliatórias, sinalizando o esforço de superação das diferenças. A discussão em torno da criação literária incita o exercício do julgamento estético, resultando em contribuições mútuas, o que torna o conceito de autoria mais complexo.

A configuração do espaço da crítica no diálogo epistolar pressupõe, em geral, o estabelecimento de pactos, mais ou menos explícitos, comumente situados nas primeiras mensagens, contrato passível, contudo, de reformulações ao longo do percurso. A correspondência entre Mário de Andrade e Manuel Bandeira nasce sob o signo do descompasso. Mário não se mostra capaz de compreender a "laboriosa e voluptuosa manipulação de alquimia subjetiva, com incalculável arsenal de subentendidos imponderáveis" (MORAES, 2001, p. 6o), previsto 
em "Debussy", poema em Carnaval; Bandeira, cumprindo uma leitura desimpedida de Pauliceia desvairada, a pedido do autor, se revela avesso aos "desvairismos gongóricos" entrevistos nos versos, a algumas "rimas e muitos ecos interiores", a "certo resíduo passadista" e aos "neologismos" com "ar muito novo", avaliações com fundamentação técnica de mistura com "idiossincrasia” (MORAES, 2001, p. 69-70). O desafinamento inaugural, colocando lado a lado a incompreensão de um e a "franqueza" de outro, longe de ferir susceptibilidades e ocasionar a morte da conversação, acaba por se constituir estimulante desafio.

Bandeira, diante da interpretação desacertada que Mário de Andrade faz de seu poema, valoriza a diferença de sensibilidades: "E o meu 'Debussy'? Tristeza! Incomunicabilidade dolorosíssima das almas! Você não sente Debussy como eu: ainda bem! Sinal que não somos banais" (MORAES, 2001, p. 66). Mário, pela vez dele, encontra nessa visão positiva do confronto de ideias, assim como nos reparos feitos à sua obra, a ocasião para definir um pacto que poderia orientar o procedimento crítico da troca de cartas: "Para mim a melhor homenagem que se pode fazer a um artista é discutir-lhe as realizações, procurar penetrar nelas, e dizer francamente o que se pensa" (MORAES, 2001, p. 72). Tratase, à primeira vista, de uma percepção unilateral ("para mim"), mas a formulação ambiciona, certamente, o engajamento do outro no processo, afinal correspondência presume reciprocidade.

O pacto edifica os alicerces de um método crítico. No primeiro termo ("discutir-lhe as realizações"), vigoram a afinidade e a predisposição para avaliar a produção do outro. Entretanto, essa avaliação, recusando-se a estiolar-se no gosto diletante, escora-se no trabalho de compreensão da obra ("procurar penetrar nelas"), tendo em mira o conhecimento consistente de sua engrenagem formal e estética. No terceiro termo ("dizer francamente o que se pensa"), viceja a síntese do processo de apreciação e a superação dele, considerando-se o posicionamento ativo do autor, aberto para a discussão. Tudo somado, afinidade, conhecimento técnico/estético e crítica em marcha forjam o mecanismo que dará o empuxo à carteação, em bases igualitárias. $\mathrm{O}$ pacto desarma a possibilidade de prevalência de um escritor sobre o outro, rasurando o espectro fantasmático das relações de poder que, inelutavelmente, assombram as amizades no campo intelectual, artístico e literário. No lugar do desnivelamento, impõe-se a figuração do alter ego, ou seja, a percepção do outro como desdobramento do eu, em termos de uma consciência cúmplice, mas questionadora.

Manuel Bandeira, em outubro de 1924, após a leitura de Clã do jabuti que Mário lhe enviara em manuscrito, exprime de forma contundente a 
significação de alter ego delineada nas cartas. Ao devolver os poemas, alerta:

Li-os, reli-os e, como fiz de outras vezes cortei, emendei, ajuntei, pintei o sete! Tudo, porém, a lápis e levíssimo, de sorte que facilmente se apagam! Fiz como se os versos fossem feitos só para mim e muitas vezes mesmo por mim. Sou o teu maior admirador, mas a minha admiração é rabugenta e resmungona (MORAES, 2001, p. 130).

A autonomia crítica ("pintei o sete") cuida para não invalidar a produção alheia, afinal, as notas apenas sugerem ("a lápis e levíssimo") outras possibilidades de estruturação poética. A firmeza de julgamento convive, assim, com gestos de cordialidade. Duas perspectivas críticas habitam o manuscrito em jogo; a de Mário, em latência, nas escolhas prévias que resultaram na versão partilhada; a de Bandeira, emulando o papel de autor dos versos, na expectativa de colaborar para que a obra fique melhor, ato que pressupõe conhecimento profundo do artefazer do outro, assim como a identificação de expectativas em relação ao ideário estético modernista. O diálogo no manuscrito desdobra-se no diálogo da carta, ocasião em que Bandeira assinala poemas destoantes do conjunto e indica, nos versos de "Noturno de Belo Horizonte", a traição do prosaísmo, vocábulos inadequados, aliterações ociosas etc. A dupla visada crítica de Bandeira ecoa no processo de criação de Mário, pois este irá acatar sugestões recebidas, segundo se depreende de sua mensagem de 7-8 de novembro. O embate gramatical ganha contornos nesse momento, quando Mário assevera: "Em vez de 'Embala-lhe o dormir', pus 'Lhe embala o sono', com o pronome errado. Sobre isso, Manuel estou disposto a me sacrificar" (MORAES, 2001, p. 146).

O empenho em colaborar no trabalho de criação literária alheia orienta, efetivamente, o desenrolar do diálogo por carta. Bandeira, em 1925, no poema "O anjo da guarda", substitui a expressão "para ao pé de mim" por outra, para evitar o cacófato "paraopeba", acusado por Mário (MORAES, 2001, p. 232). Este, em 1927, diante de uma opinião inteiramente desfavorável do amigo acerca dos versos de "Vitória Régia", o transmuta na prosa poética de uma das entradas do diário do Turista Aprendiz (MORAES, 2001, p. 350). Muitos são os exemplos de cooperação, como pude examinar em outra oportunidade'.

O acordo de interlocução crítica abre-se para reverificações ao longo da correspondência, conforme se observa na mensagem de Mário

1. Cf. "Afinidades eletivas" (MORAES, 2001, p. 13-28). 
de Andrade a Bandeira, em 12 de dezembro de 1925, quando o assunto gira em torno da natureza da camaradagem que tinham construído a distância, inventada, portanto, na escrita:

[...] quando você me faz qualquer reparo, geralmente aceito (até uns tempos andei aceitando com docilidade por demais) e quando não aceito modifico, parafuso, repenso, trabalho e sempre fico numa dúvida baita. Isso prova que sei que você me aprecia porque aprecia mesmo, com inteligência, com crítica, com independência de coração. [...] Você comenta que a nossa amizade é carteada... Isso não quer dizer nada, Manu! Isso é que é o mais puro mais elevado mais masculino feitio e manifestação de amizade. Você me quer um bem danado no que aliás tem certeza que é correspondido ponto por ponto. Repare no carinho infinito, atenção paterna com que você quer que as minhas coisas fiquem excelentes (MORAES, 2001, p. 261).

Mário argumenta em favor do caráter legítimo da relação de amizade urdida essencialmente por meio de cartas. De modo enviesado, referese às vicissitudes da conquista de um vínculo intelectual simétrico, no emparelhamento de dois homens que se veem no mesmo plano de cultura e lugar social, em sintonia na vanguarda literária modernista. Mário, como se nota, julga arriscada a própria "docilidade" em acolher a opinião do interlocutor, pois isso poderia acarretar o desequilíbrio no diálogo, diminuindo a eficácia da correspondência, enquanto efetivo campo de provas.

Se o pacto definido na troca epistolar pressupõe afinidades e negociação de diferenças, suscitando a interação de percepções estéticas, não elide as situações que levam a posicionamentos irreconciliáveis. Estes, em grande medida, configurando-se como proposições de autonomia crítica, podem garantir o equilíbrio da relação intelectual. Caberia, assim, analisar algumas dessas situações de choque entre diferentes concepções interpretativas, no âmbito da criação literária. O agudo antagonismo, entretanto, vale observar, não provocou o esgarçamento da correspondência, nem a ruptura da amizade. Circunstância paradigmática pode ser vislumbrada no embate acirrado em torno do processo de elaboração de Macunaíma, em particular, no que tange à pertinência da "Carta pras icamiabas" na rapsódia.

Macunaíma, tirado do prelo em julho de 1928, ganhara uma primeira versão entre 16 e 23 de dezembro de 1926 e uma segunda entre 23 de dezembro desse ano e 13 de janeiro de 1927, como testemunha a anotação de Mário de Andrade no manuscrito remanescente da obra (ANDRADE, 1996, p. 437). Na base do intenso fluxo criador, enraizava-se "todo o preparo formidavelmente grande anterior", segundo informaria o autor em carta a Manuel Bandeira, em agosto de 1931 (MORAES, 2001, p. 519). 
Ao mesmo amigo, em 7 de novembro de 1927, explicitou os vínculos do herói de sua narrativa com o deus indígena sul-americano, Macunaíma, que transita no segundo volume do Vom Roroima zum Orinoco - Mythen und Legenden der Taulipang und Arekuná Indianern (1924), do etnógrafo alemão Koch-Grünberg. Na primeira fase de construção do "herói sem nenhum caráter", abarcando leituras, pesquisas prévias e a redação de duas versões do texto, Manuel Bandeira não tem participação e, certamente, nem mesmo devia saber que a obra estava em progresso; entre janeiro e março de 1927, andava pelo nordeste, intermediando negócios da Agência Brasileira S.A.

Antes que Bandeira viesse a ler a sumária referência a Macunaíma, na carta de Mário de Andrade, em 6 de abril de 1927, outros correspondentes do autor tiveram notícia da obra. O jovem escritor de Minas Gerais, Carlos Drummond de Andrade, ao receber a mensagem de Mário, de 18-19 de janeiro de 1927, soube do "romance engraçado" (SANTIAGO; FROTA, 2002, p. 264-6) e do nome dos capítulos. Tendo o moço manifestado curiosidade pelo relato ficcional, o autor, no mês seguinte, patenteia suas intenções, afirmando que procurou

caracterizar mais ou menos foi a falta de caráter do brasileiro [...] Os caracteres mais principais que a gente percebe no livro são a sensualidade, o gosto pelas bobagens um certo sentimentalismo melando, heroísmo coragem e covardia misturados, uma propensão pra política e pro discurso. Porém nem tive intenção de fazer um livro importante de psicologia racial não (SANTIAGO; FROTA, 2002, p. 276).

Em 1o de março, Mário consulta o potiguar Luís da Câmara Cascudo acerca da existência de "lenda [...] bem lírica, sentimental" no Nordeste. Pedia uma narrativa folclórica regional para integrá-la na ficção, pois tencionava aproveitar "no máximo possível lendas tradições costumes frases feitas etc brasileiros", em uma perspectiva nova, ou seja, na intenção de misturar "completamente o Brasil todinho" (MORAES, 2010, p. 123). Em 9 de fevereiro, a pintora Anita Malfatti fica a par da novidade: "Fui na fazenda passar um mês. Pois me veio o saci duma ideia pra um romance na cabeça, escrevi o tempo todo, teve dias em que escrevi até duas da manhã! trouxe mais um livro na mala [...]" (BATISTA, 1989, p. 129).

Manuel Bandeira, em 31 de outubro de 1927, comunica o recebimento e a leitura de Macunaíma. Decerto tinha sob os olhos o datiloscrito da obra que, no dia 4 desse mês, o amigo lhe contara que estava "passando a limpo" (MORAES, 2001, p. 356). Exprimindo o seu juízo crítico, Bandeira alude a conversas anteriores sobre o assunto do livro, mas não se pode 
saber com certeza se estas foram presenciais ou assentadas em cartas das quais hoje não se conhece o conteúdo. Confessa ter "gostado" do escrito, julgando "excelentes" os dois primeiros capítulos, retratando Macunaíma menino. "Estupendo", para ele, a "unificação artística do fundo popular brasileiro". Valia, ainda, a menção ao "processo rabelaiseano das enumerações" e certos achados, como o uso, na clave eufemística, do verbo "brincar" e da expressão "agora estão se rindo um pro outro" (MORAES, 2001, p. 358).

Em contrapartida, sem se valer de artifícios retóricos contemporizadores, Bandeira descobre "partes paus" na obra, seja em passagens de Macunaíma homem, seja nos capítulos "em que se adensam algumas lendas cheias de detalhes como 'Uraricoera' e o $3^{\text {o ' }} \mathrm{Ci}$, Mãe do Mato”, que considera "descosido”. Detendo o olhar no desfecho da história, no qual o protagonista, despedaçado pela Uiara, sem a perna direita, vai "viver o brilho inútil das estrelas", transformando-se na Ursa Maior, avalia que a constelação do herói foi "mal escolhida", "tinha que ser [...] austral." Em tom mais rude, escacha a "Carta pras icamiabas":

\begin{abstract}
tem uma coisa francamente ruim, - rui - a epístola às Amazonas. Não percebi a sua intenção escrevendo em arremedo de clássico. Aquilo está de uma paulificação horrorosa. O seu "vernáculo" não tem sabor nenhum, nem se compreende por que cargas d'água Macunaíma de repente dispara a escrever feito o Laudelino Freire. [...] essa coisa me parece um bruto defeito, um desconchavo enorme, sem a menor graça e até parecendo pretensioso (MORAES, 2001, p. 358).
\end{abstract}

Ciente de que a obra estava em processo, Mário certamente contava com o parecer do amigo para avaliar a consistência do projeto literário. As restrições feitas por Bandeira, assim, exigem do autor a releitura da narrativa, seja para sustentar as escolhas feitas, seja para reconhecer a pertinência do alvitre alheio, suscitando a reconfiguração do texto.

Acompanhando-se a negociação dos interlocutores em torno de três dos pontos frágeis detectados por Manuel Bandeira em Macunaíma, logra-se captar na correspondência as tensões associadas ao trabalho literário compartilhado em bases intelectuais não hierarquizadas. Se, para Bandeira, "Ci, Mãe do Mato" carece de unidade narrativa, o autor "protest[a] aos berros", em sua resposta, argumentando longamente em defesa daquele capítulo que, muito ao contrário, acha "o melhor do livro" (MORAES, 2001, p. 359). Em face da discordância, o autor de Libertinagem repassa o capítulo, mas o julgamento exposto na carta de 6 de novembro se confirma; o trecho, para ele, é mesmo "cacete". Explica-se, procurando demonstrar a "desproporção guaçu” (problema estrutural, portanto) 
observada na sequência que junta o encontro de Macunaíma com $\mathrm{Ci}$, a viuvez do herói e o "caso da cascata". Para aperfeiçoá-lo, parece-lhe "evidente" que "os amores com $\mathrm{Ci}$ deviam exigir um bom capítulo só pra eles com muita brincadeira [...]" (MORAES, 2001, p. 360-1). Em 7 de novembro, Mário dá o braço a torcer: "Onde você me despertou bem a crítica e resolvi fazer que nem você fala é no Caso de Ci. Vou fazer um capítulo só pros amores dela. O resto passa pra outro capítulo. Essa crítica foi uma revelação luminosa nesta carta. Vai melhorar enormemente o caso". Intui, todavia, que será "perigoso" inserir novas estripulias sexuais no enredo, receando não "atingir o inédito forte que tem na cena-deamor do $1^{\circ}$ capítulo e deste em Ci" (MORAES, 2001, p. 364).

O confronto atingia uma estabilidade momentânea; o texto da primeira edição de Macunaíma acolheria a sugestão de Bandeira. Tratase, contudo, de um equilíbrio instável, pois, em carta em 29 de agosto de 1928, pouco depois, portanto, da publicação da obra pelo estabelecimento gráfico paulistano de Eugênio Cupolo, o autor recua um pouco. Mário confirma que a remodelação de "Ci, Mãe do Mato" resultara do "conselho" do destinatário:

Se lembre que você me falou que pela importância que Ci tinha no livro, os brinquedos com ela estavam desimportantes por demais. Então matutei no caso, achei que você tinha razão e todas aquelas safadezas vieram então. [...] Estou convencido que exagerei. [...]. Se Macunaíma algum dia tiver a honra duma segunda edição acho que refundo aquilo (MORAES, 2001, p. 402).

De fato, a reedição da obra, em 1936, pela José Olympio do Rio de Janeiro, sequestraria as cenas picantes acrescentadas no reconto. De todo modo, a percepção crítica de Bandeira permaneceria ecoando na rapsódia, manifestada na recomposição do capítulo, permitindo que se colocasse em relevo, na estrutura da obra, a experiência amorosa do "herói da nossa gente".

Macunaíma, em sua primeira edição e nas duas seguintes que Mário de Andrade teve a oportunidade de acompanhar, consolida "Ursa Maior" como o penúltimo capítulo. O herói, "com todo o estenderete dele, galo galinha revólver relógio” (ANDRADE, 1996 [1928], p. 166) vai se espraiar no firmamento, por artes mágicas do Pauí-Pódole, sob a forma do grupo de estrelas que nomeia o episódio no livro. A decisão do autor contraria a ponderação de Bandeira na carta de outubro de 1927, estimando a designação inadequada. Na ocasião, Mário, inversamente, reafirma que a constelação tinha sido "muito bem escolhida"; justificase fornecendo subsídio erudito e a experiência pessoal: a "Ursa Maior se refere, diz um professor deutsch, ao saci, por causa da perna só que 
ele tem. [...]. E se vê de todo o nosso céu, não se vê? Eu a enxerguei do Amazonas a São Paulo" (MORAES, 2001, p. 359). Telê Ancona Lopez, deslindando matrizes e intertextos da rapsódia, recupera, nesse capítulo, a presença do astrônomo alemão Lehmann Nitsche, autor de Mitologia Sudamericana, que compreendia a Ursa Maior como o Grande Saci, assim como a referência a Gonçalves Dias, que “n'O Brasil e a Oceania, apoiado em Barleus" a considerava "signo de um paraíso perdido, na mitologia do índio” (LOPEZ, 1996, p. XXXI). Bandeira resiste, fornecendo o relato da própria vivência:

\footnotetext{
A Ursa Maior vê-se no Norte, mas daqui do Rio só um pedaço muito baixo no horizonte durante pouco tempo e em certa época do ano. Tenho certeza disso porque andei procurando na época mais favorável. É caracteristicamente uma constelação boreal quase no pólo celeste (MORAES, 2001, p. 361).
}

Testemunho contra testemunho, prevalece na ficção o Mário leitor, escudado em livros de sua biblioteca.

A tensão mais acerba no debate em torno da feitura de Macunaíma se dá em relação à “Carta pras icamiabas”. Na versão publicada em 1928, a extensa missiva do herói, escrita na capital paulista, aos 30 de maio de 1926, endereçada às suas súditas, situa-se no centro da rapsódia, o capítulo IX. Macunaíma pede dinheiro (bagos de cacau) para custear suas gaiatices, encontrando espaço para relatar a experiência urbana, à moda dos viajantes coloniais. Tanto quanto o assunto tratado, chama a atenção a linguagem da Carta, arremedo jocoso do português castiço, com as escorregadelas do remetente no uso de certas expressões, pondo a nu a sua obsessão sexual. Como se viu, Manuel Bandeira, na leitura do manuscrito da ficção, repudia o trecho, considerando-o "francamente ruim".

A avaliação adversa impõe ao autor, em sua resposta, a caudalosa explicação do "milhão de intenções" subjacente ao capítulo. Para Mário de Andrade, aspirando apreender traços da psicologia coletiva nacional, interessava colocar sob o foco, tendo em vista a atitude pedante do herói, o vezo do letrado brasileiro em escrever "português de lei", sob as ordens da Academia de Letras. Na sátira, o autor aproveita para rir dos "cronistas nossos (contadores de monstros nas plagas nossas e mentirosos a valer) e [do] estado atual de São Paulo, urbano, intelectual, político, sociológico”. A Carta pretendia também marcar a diferença de expressão entre um intermezzo narrativo pretensioso e a "linguagem literária" desataviada dos outros capítulos. A inabalável defesa da presença da Carta no entrecho ("não tiro ela não porque gosto muito dela") não impede, contudo, o surgimento da autocrítica: "[a carta] me desgosta em dois 
pontos: parece imitação do Osvaldo e de certo os preceitos usados por ele atuaram subconscientemente na criação da carta e acho comprida por demais. O primeiro ponto não acho remédio. O segundo, vou encurtar a carta" (MORAES, 2001, p. 359-6o). Se o vínculo com Oswald de Andrade, na cruzada contra o bacharelesco dominante na expressão literária, deve ser assumida como realidade inescapável da concepção da Carta, a pequena margem de negociação do autor com Manuel Bandeira situa-se no reconhecimento da hipertrofia do capítulo, em número de páginas. Fazendo alguma concessão, talvez Mário tivesse a expectativa de receber do camarada sugestões de pequenos cortes no escrito, assinalando extratos subsidiários ou de pouca força derrisória.

Contudo, o que veio do Rio de Janeiro, na mensagem de 6 de novembro, foi a reiteração do alvitre anteriormente exposto. A Carta, para Bandeira, era mesmo "detestável pela linguagem"; reconhecia o impasse, pois nessa questão se mostravam "inconciliáveis" (MORAES, 2001, p. 361). Mário, em sua resposta, finca o pé, exigindo considerações mais sólidas:

$\mathrm{Na}$ "Carta pras icamiabas" não cedo até agora mais do que cedi. Reduzo um pouco e isso mesmo porque já sentia que estava comprido por demais. Você conseguiu fortificar o sentimento. No resto os argumentos de você são de ordem puramente sentimental e não de ordem crítica e são inaceitáveis. Não gosto porque não, porque é pretensioso, porque me aporrinha, são argumentos sem valor intelectual (MORAES, 2001, p. 364).

Bandeira, em 12 de novembro, investe-se de argumentos para provar ao autor que o capítulo estava em desacordo com a formulação da psicologia de Macunaíma, a qual deveria ser "determinad[a] pelo caráter de criação popular". Nesse sentido, o herói, "com vaidade de escrever com sabor clássico", representava um "disparate, uma quebra violenta da unidade da personagem” (MORAES, 2001, p. 364).

Mário de Andrade convalida, em 27 de novembro, a solidez das "contestações" (MORAES, 2001, p. 368) de seu interlocutor, que se mantinha aferrado à ideia de supressão da Carta, ou ainda de uma eventual reformulação que botasse o herói, de regresso ao rincão natal, a contar para as icamiabas as aventuras na cidade grande, "em linguagem de imperador de folclore brasileiro" (MORAES, 2001, p. 358). As ponderações de Bandeira, entretanto, não sensibilizam o autor, pois este irá redarguir, sinalizando que, na construção da personagem, estava prevista a falta de lógica de seus gestos, já que é "uma contradição de si mesmo". Se, afavelmente, promete matutar sobre o assunto, não deixa dúvida de que a sua vontade não se encontra inteiramente abalada. Ampara a decisão 
de manter a missiva do herói na opinião de outro leitor do manuscrito, cujo nome não declina: "você acha a 'Carta' pau, mas um outro que leu e tem muita inteligência também, achou boa. Enfim vou matutar e fique descansado que matuto sem nenhuma paixão. É certo que gosto da carta, isso gosto. Enfim vou pensar" (MORAES, 2001, p. 368)².

A tensão criada e não resolvida, no tocante à "Carta pras icamiabas", no processo de elaboração de Macunaíma, tem desdobramentos, quando a obra chega, impressa, aos companheiros do círculo modernista e aos críticos. Entre estes, Alceu Amoroso Lima, em O Jornal do Rio de Janeiro, assegura que "o livro é longo demais. Cacete muitas vezes, como na imensa carta, em estilo médico-purista, que o nosso herói escreve às suas súditas do Uraricoera, bancando a lettre persane" (RAMOS JR, 2012, p. 270). Nestor Vítor, em $O$ Globo carioca, fere a mesma corda, avaliando que a ficção traz novidade, "mas só até quando se chega a uma carta do herói, escrita por deboche num português pseudoclássico. Isso faz contraste tão violento com o que lêramos antes, que se começa a bocejar sem querer. É uma falta imperdoável na estética do livro" (RAMOS JR, 2012, p. 290). Outro crítico da velha guarda, João Ribeiro, sem mencionar diretamente a Carta, valoriza tema levantado por ela, ao sublinhar "páginas de relevo" na obra, como "a distinção da língua falada e da escrita” (RAMOS JR, 2012, p. 295); resgatava, assim, o espanto do herói diante da terra dos paulistanos, onde a "riqueza de expressão intelectual é tão prodigiosa, que falam numa língua e escrevem noutra” (ANDRADE, 1996 [1928], p. 84).

Manuel Bandeira, ao comunicar a releitura de Macunaíma, na carta de 23 de agosto de 1928, embora afirme ter ficado "querendo mais bem ao herói”, repisa sua antipatia por aquilo que se tornara, na conversação do ano anterior, o pomo da discórdia: "Só não vou com a 'Carta às icamiabas'. Paciência. Pode quem quiser gostar daquilo, inclusive você, eu acho uma besteira” (MORAES, 2001, p. 399). Diante da sentença epigramática, inteiramente restritiva, Mário, achando graça na celeuma criada em torno da missiva do herói, deixa entrever, em sua resposta, em 10 de setembro, um importante documento acerca da circulação de ideias e valores estéticos na rede de sociabilidade modernista:

2. Cabe registrar que, em 5 janeiro de 1928, a rapsódia volta a ser assunto na correspondência, quando Mário pede a colaboração de Bandeira para o desenvolvimento de certo trecho da rapsódia: "Olhe, pergunte como coisa de você, pro Gilberto [Freyre] se ele sabe o nome de alguma rendeira célebre de Pernambuco ou do Nordeste qualquer. Se não for de Pernambuco ele que diga donde ela é. É pro Macunaíma. Não diga que é coisa minha senão ele é capaz de fazer perfídia e dar nome errado só pra ter o gosto de ler besteira." (MORAES, 2001, p. 372). 
Tenho me divertido é com o caso da "Carta". Você inda tem razão, não concordo mas tem, porque acha a carta besta, julga a carta em si. [...] A carta é um intermezzo. Fatigante, intolerável pra uns, pra outros tem sido um gozo. Osvaldo gosta muito dela. P. Prado também. [...] O Couto, você é um safado, mande me contar se por acaso falando no livro aí você não contou que não gostava da carta, diz que Prudentico, Rodriguinho também não gostam dela, estou imaginando uma sugestão que estou longe de imaginar qualquer intenção maldosa de você está claro. Pois o Couto, o que me falara foi da carta. Gostou muito e até só por atrapalhações não transcreveu parte dela no Diário. Foi pra aí e voltou também não gostando da "Carta” já antes gostada. Filhodaputei ele, ficou cheio de mãos, se borrou dizendo que gosta da carta em si, não no livro - o contrário de você. Tarsila gosta da "Carta". Tou com vontade de fazer uma estatística (MORAES, 2001, p. 406).

O burburinho provocado pela Carta irá reverberar na atividade criadora de Mário de Andrade, pois, na republicação da obra, o capítulo exibe três expressivos cortes, além de outros reparos de menor monta. Constata-se, desse modo, um vigoroso dinamismo na produção do escritor, que não prescinde da colaboração de seus pares, na reformulação do texto, tendo em vista novas percepções críticas. Se a obra em processo pode acolher contribuições alheias, também se configura o espaço das tensões, quando o criador defende a legitimidade e a consistência de suas escolhas.

A correspondência entre Mário de Andrade e Manuel Bandeira instaura, em alguns momentos, como se pôde acompanhar, curtoscircuitos. Na elaboração de Macunaíma, o autor acolhe a sugestão de acréscimo no capítulo "Ci, Mãe do Mato", mas depois recua, rasurando-a na reedição do texto; não negocia a mudança do nome da constelação no fecho da rapsódia; defende com vigor a importância da "Carta pras icamiabas" na engrenagem ficcional, aceitando apenas cumprir pequenos ajustes, no que tange à extensão do escrito. Confrontos estéticos e linguísticos balizam o intenso diálogo crítico. A existência do impasse confirma a grandeza dessa troca epistolar no campo literário do modernismo brasileiro, pois traz à luz o complexo funcionamento de relações intelectuais e artísticas negociadamente simétricas.

\section{REFERÊNCIAS BIBLIOGRÁFICAS}

ANDRADE, Mário de. Macunaíma o herói sem nenhum caráter. Edição crítica de Telê Porto Ancona Lopez. 2. ed. Madri: ALLCA XX, 1996.

BANDEIRA, Manuel. Poesia e prosa. V. II, Prosa. Rio de Janeiro: Aguilar, 1958. 
BATISTA, Marta Rossetti (org.). Mário de Andrade: cartas a Anita Malfatti (1921-1939). São Paulo: Forense, 1989.

LOPEZ, Telê Ancona. Nos caminhos do texto. In: ANDRADE, Mário de. Macunaíma o herói sem nenhum caráter. 2. ed. Madri: ALLCA XX, 1996.

MORAES, Marcos Antonio de (organização, introdução e notas). Correspondência Mário de Andrade E Manuel Bandeira. 2.ed. São Paulo: Edusp, 2001. . (organização, notas e posfácio). Câmara Cascudo e Mário de Andrade: cartas, 19241944. São Paulo: Global, 2010.

RAMOS JR., José de Paula. Leituras de Macunaíma: primeira onda (1928-1936). São Paulo: Edusp/ Fapesp, 2012.

SANTIAGO, Silviano (prefácio e notas); FROTA, Lélia Coelho (organização e pesquisa iconográfica). Carlos E Mário: correspondência completa entre Carlos Drummond de Andrade (inédita) e Mário de Andrade. Rio de Janeiro: Bem-Te-Vi, 2002. 
